GEORGE REYES

\title{
EPISTEMOLOGÍA HERMENÉUTICA ANALÓGICA PARA LA INTERPRETACIÓN \\ DE LA NARRACIÓN BÍBLICA
}

\section{Planteamiento del problema}

Una de las tendencias más fuertes en el contexto hermenéutico bíblico contemporáneo, tanto académico como eclesiásticopastoral, es la práctica de una interpretación excesivamente light del texto narrativo y de otros géneros bíblicos; es nuestra opinión que esta hermenéutica ha corrido y corre el riesgo hoy de conducir a una interpretación que no hace justicia al texto, por estar ella basada sobre una epistemología débil, es decir, una epistemología excesiva y unilateralmente intuitiva y experiencial (lado subjetivo de toda interpretación), e ideológica particular, ${ }^{1}$ sin que medie en ella un acto y proceso hermenéutico metodológico consciente que le haga justicia ni una conciencia de la subjetividad de todo sujeto interpretante (hombre o mujer $)^{2}$ ni otra analógica. Nos parece que, en nuestro contexto, este

1 Uso la frase "agenda ideológica" en un sentido amplio que incluye la netamente política - de izquierda o derecha- y la conformada por una gama de intereses existenciales que guían la lectura del texto.

2 Es lo que Gadamer ha denominado "historia efectual", es decir, el influjo poderoso de la propia situacionalidad o ubicación en un contexto histórico- 
fenómeno ha redundado en una verdadera crisis hermenéutica tanto en la academia (manuales de hermenéutica) como en la iglesia cristiana (púlpito de predicación y enseñanza). Y esta crisis exige no sólo de un método hermenéutico de interpretación del texto conforme a su género, sino también de una razonable fundamentación epistemológica analógica que contribuya a justificar mejor la propia naturaleza del acto y proceso hermenéutico de interpretación y, así, a equilibrarlo; de este modo, podríamos evitar que ese acto y proceso opere totalmente con base a la epistemología hermenéutica clásica moderna ni con base a la de aquella posmoderna contemporánea, que tienden, la primera, a reducir temerosamente al máximo la subjetividad y la polisemia, y, la segunda, y contrariamente, a magnificarlas $y$, por ende, a dispersarse indebidamente en el relativismo y escepticismo propio de Nietzsche y Derrida.

A la luz de lo anterior, en este breve trabajo la intención es proponer un modelo epistemológico para la interpretación del texto especialmente narrativo: ${ }^{3}$ el analógico. Con este fin, primeramente, y como trasfondo para la propuesta, describo más ampliamente el escenario epistemológico contemporáneo; seguidamente, describo la analogía; finalmente, discuto el modo cómo la analogía contribuye a una interpretación equilibrada del texto en mención. He de anticipar que la naturaleza de esta propuesta es explorativa, no final.

\section{EI escenario epistemológico contemporáneo}

No cabe duda que en la hermenéutica occidental, argumenta Beuchot (2007, pp. 11-50), han convivido a través del tiempo - y de hecho hasta el presente- dos figuras epistemológicas básicas ${ }^{4}$ en

cultural y religioso determinado del que nadie puede abstraerse. Cfr. G. H. GADAmer, Verdad y Método II. Salamanca, Sígueme, 1998.

3 Aunque mi énfasis está en el texto narrativo, la analogía puede ser adoptada en la interpretación también de otros géneros literarios bíblicos.

${ }^{4}$ En realidad, la epistemología hermenéutica analógica también, de un modo u otro, ha corrido paralelamente a esas dos figuras (ver M. BEUCHOT, Perfiles presenciales de la hermenéutica. México, Universidad Nacional Autónoma de México, 2005, pp. 91-102). En otra de sus obras (Compendio de hermenéutica analógica. México, Torres Asociados, 2007, p. 22; Posmodernidad, hermenéutica y analogía. México, Universidad Intercontinental, 1996, p. 35) BEUCHOT considera que, aunque de un modo periférico, en los últimos años ella sí ha estado presente en algunos pequeños sectores de la epistemología reciente, en la poética del mexicano Octavio Paz y en una de las vertientes actuales de la filosofía: la hermenéutica, en la de Paul Ricoeur $-y$, a mi modo de ver, en la de G.H. Gadamer, con su énfasis en la "prudencia"-, si bien Ricoeur, arguye Beuchot, se habría de quedar muy corto. De esa cuenta, por un lado, Beuchot (Perfiles presenciales de la 
oposición que resumiré a continuación, con riesgo de una simplificación, generalización ${ }^{5} \mathrm{y}$ exageración excesiva para hablar de predominio $\mathrm{y}$ darme a entender.

Por un lado, está la clásica excesivamente rigurosa y pretenciosa de cientificidad, objetividad -del sujeto (intérprete/científico) y objeto (texto) del saber- y hasta de exhaustividad: la univocista, cuyo ideal en la interpretación camino al acceso del saber es la univocidad propia de los cientificismos y positivismos modernos, ${ }^{6}$ es decir, una sola interpretación de la verdad válida, clara (sin opacidad), transparente (pura, sin contaminación ), exacta, exhaustiva y ubicua, es decir, idéntica-en-todos-los-sujetosalrededor-del mundo; ${ }^{7}$ de esa cuenta, la interpretación de esa verdad

hermenéutica. México, Universidad Nacional Autónoma de México, 2005, pp. 1112) considere que la hermenéutica haya estado asociada a la sutileza (capacidad de traspasar el sentido superficial y de discernir más de un sentido); por otro lado, hablar de analogía en la hermenéutica no sería nuevo; lo que sí es nuevo es su redescubrimiento y aporte frente al univocismo y equivocismo hermenéutico que arrecia en todos los campos, por lo cual - valga la aclaración- a lo largo de este trabajo enfatizo más ese equivocismo.

$5 \mathrm{Ni}$ hay la intención de caricaturización alguna. En todo caso, como lo digo enseguida, la intención es hablar de predominio y darme a entender.

6 Por ejemplo, la filosofía analítica, cuya epistemología ha sido acusada de haber querido imponer un solo método para hacer ciencia, privilegiando así lo común y la mismidad del discurso. Irónicamente, se sabe que de esta corriente analítica sale una línea de académicos que propician una epistemología posanalítica (posmoderna) pluralista y anarquista como Paul Feyerabend y Richard Rorty; por eso, algunos autores hablan ya de una época pos-analítica.

7 Ya en la época griega, Platón se inclinaba a ese ideal univocista y más adelante, en la época patrística (inicio o antesala de la Edad Media), éste estaba viviente en la escuela de Antioquía que privilegiaba una interpretación literal o unívoca de la Escritura y rehuía de la alegórica, simbólica o espiritual propio de la escuela rival: la de Alejandría, vinculada al platonismo, con Orígenes a la cabeza. Durante la escolástica, Renacimiento e Ilustración el ideal en cuestión continuaría vigente (por ej.: Schleiermacher, 1768-1834, en cuanto hermeneuta "romántico", y Calvino y Lutero) hasta el contexto contemporáneo -por ej.: en la filosofía analítica, estructuralismo y hermenéutica filosófica (Apel, Habermas, Eco y otros) y bíblica (Hirsch y, en Hispanoamérica, la mayoría de intérpretes, hermenéuticas textuales y manuales de hermenéutica- en que se ve puesto en crisis y continúa experimentando mutaciones con el embate de la figura epistemológica equivocista y la analogía como una vía para el acceso al saber desde finales del siglo XX; Cfr. Beuchot (Posmodernidad, hermenéutica y analogía. pp. 9-12; Historia de la filosofía del lenguaje. México, Fondo de Cultura Económica, 2005, pp. 21-24); P. L. SOTOLONGO CODINA Y C. J. DelGADO DíAZ, «La epistemología del segundo orden» en Sotologo Codina / DelGado Díaz (eds.), La revolución contemporánea del saber y la complejidad social, 2006, pp. 47-50; J.R. SANABRIA, «Filosofía y hermenéutica», en J.R. Sanabria / M. Beuchot (eds.), Algunas perspectivas de la filosofía actual en México, México, Universidad Iberoamericana, 1997, pp. 44-49); P. RicoeUR, 
—no contaminada por la situacionalidad y subjetividad del investigador o de la investigadora- correspondía, exacta y totalmente, a la inherente del objeto interpretado: el texto (Reyes, 2009, pp. 81-108). ${ }^{8}$

Por otro lado, está la figura epistemológica equivocista. Esta refleja los rasgos de la cultura y corrientes filosóficas posmodernas contemporáneas $^{9}$ y es propia de la mayoría de las tendencias hermenéuticas posmodernas, académicas o pastorales, ${ }^{10}$ con su práctica y

Hermeneutics \& the Human Sciences, Cambridge, Cambridge University Press, 1981, pp. 45-48; Del texto a la acción: Ensayos de hermenéutica II, Buenos Aires, Fondo de Cultura Económica, 2000, pp. 73-76).

8 Así, la noción de verdad en la figura epistemológica moderna era la de una "verdad por correspondencia"; obviamente, esta noción no toma en cuenta el ángulo subjetivo de la verdad, incluso bíblica, que es parte de la naturaleza analógica de la misma; ver Reyes (2009, pp. 81-88) contra Sotolongo Codina y Delgado Díaz (op. cit., pp. 47-50), quienes, olvidando esa naturaleza analógica de la verdad, la subjetivizan posmodernamente, si bien reconocen la intersubjetividad del o de la intérprete o del investigador o de la investigadora social; sin embargo, es sabido que, siguiendo a Nietzsche hoy se interpreta la verdad como una ilusión antropológica que intenta dar sentido a lo "real", o como una metáfora que ha olvidado que ha olvidado su propia condición ilusoria; esta es la conclusión a la que Derrida (La diferencia. 1968) pareciera llegar.

9 Beuchot (Posmodernidad, hermenéutica y analogía. pp. 12-14) hace una breve descripción de esta cultura ambigua y difícil de apresar, cuya característica esencial es su rechazo a la razón y epistemología ilustrada moderna, que de una u otra manera ha influido en el campo hermenéutico, incluso bíblico, en el cual, en la práctica, ya no pareciera apostarse a verdades fuertes ni objetivadas; en las páginas 9-12, de esa misma obra anterior, Beuchot ofrece un breve mapeo de las diversas corrientes filosóficas posmodernas entre las que se encuentra la que ahora me refiero: aquella que sigue el pensamiento esencial y propiamente posmoderno heredado de Nietzsche, célebre filósofo alemán y "maestro de la sospecha", quien, poniendo en tela de juicio la mentalidad moderna, habría de rechazar la razón tildándola de "voluntad de poder pervertida"; Cfr. F. Nietzsche, Crepúsculo de los ídolos. Madrid, Alianza, 1998; G. Vattimo, Diálogo con Nietzche, Buenos Aires, Paidós, 2002.

10 Aunque no se puede generalizar, en determinados contextos pastorales (púlpito evangélico), sean conservadores o ecuménicos, se puede palpar lo antes argumentado en el uso frecuente, consciente o no, de una hermenéutica intuitiva y experiencial, que tiende a tanto desembocar ya sea en la más cruda alegorización o ideologización (de izquierda o derecha) del texto como a desdeñar sin criterio alguno la lectura de "mentalidad de resolver problemas" (la exegéticocrítica) y favorecer la "formativa" (la intuitiva y experiencial); en el campo ecuménico ideológico, F. REYES ARCHILA, «Hermenéutica y exégesis: Un diálogo necesario» en Revista de Interpretación Bíblica Latinoamericana 28 (1997), pp. 936 y J. S. CroAtto, Hermenéutica Bíblica, Buenos Aires, Aurora, 1984, son unos ejemplos; en el conservador un ejemplo sería lo que en una ocasión, la misma profesora (jsin formación bíblico-teológica formal!) de seminario que criticaba conscientemente la lectura exegético-crítica del texto, decía en su predicación: "No se preocupen, si no entienden lo que el texto dice; preocúpense de que los transforme"; en otras palabras, ella parecía urgir a que nadie de los presentes nos preocupáramos por una exégesis responsable del texto, puesto que, para ella, y 
promoción, consciente o inconscientemente, de una interpretación light opuesta desmedidamente a la razón y basada desmedidamente en la intuición, la experiencia o el lector. En la hermenéutica filosófica antimoderna - J. Derrida, M. Foucault, R. Rorty, F. Lyotard, G. Vattimo, Croatto $\mathrm{y}$ otros hermeneutas, $\mathrm{y}$ académicos tanto extranjeros como latinoamericanos - la oposición a la razón suele ir de la mano con la siguiente presuposición deconstructivamente escéptica: que la interpretación es tarea infinita, metafórica y en suspenso, puesto que es imposible interpretar y entender nada, ya que en el fondo de todo no hay nada original que discernir ni entender en los textos ni se puede hablar de interpretación verdadera alguna. Es que, como Beuchot (Posmodernidad, hermenéutica y analogía. pp. 10-11) observa, esta hermenéutica profesa un nihilismo de corte nietzscheano, puesto que sus teóricos

toman de la experiencia estética de la modernidad la presencia de una subjetividad descentrada, liberada de todas las limitaciones del conocimiento y la actividad intencional o finalizada, desgajada ahora de los imperativos del trabajo y de la utilidad. En nombre de esta subjetividad rechazan la racionalidad de la modernidad. Reclaman las pulsiones espontáneas de la imaginación y de la afectividad como arraigadas en un fondo arcaico, y las oponen a la razón...como algo poético y dionisiaco...Profesan una suerte de anarquismo. Denuncian la razón instrumental y por causa de ella se oponen a la razón en cuanto tal. En su lugar queda desenmascarada la voluntad de poder, el hedonismo y el cinismo

De esa cuenta, según esta mentalidad, no sólo se interpreta interpretaciones - las que deben a la vez interpretarse-, sino que también el lenguaje, considerado mediador existencial de la experiencia hermenéutica y vehículo por medio del cual se expresa la razón, se ha viciado y vaciado de significado (concepto o sentido y referencial o cosa a la que remite) y convertido en un canal de comunicación y de acceso al saber ambiguo y camuflado. ${ }^{11}$

según el contexto en que se mueve, toda exégesis es intelectualista, irrelevante (entiéndase, a las necesidades "individuales") y no dependiente del Espíritu.

11 Es ambiguo y camuflado, cuando el lenguaje tiene algo original que comunicar cosa que no siempre lo tiene. Una razón de esa ambigüedad del lenguaje es porque, entre otras cosas, éste no es instrumento para informar sobre algún mundo ya conocido (G. H. GADAMER, Verdad y método II), pero sí para encubrir y excluir lo que difiere, y sugerir sólo ausencia, pues no hay lenguaje auto-referente, sino metafórico o equívoco (Nietzsche y Derrida); es decir, no hay correspondencia exacta entre lenguaje y realidad porque el primero no espejea a la segunda, como propone la filosofía analítica del lenguaje - a la que quizás aún en la hermenéutica bíblica hemos estado acostumbrados - y aún, de algún modo, la ontología hermenéutica (Heidegger, Gadamer, Bultmann y otros); Beuchot (2005b, pp. 171-289, 303-313); Ricoeur (2003); Sanabria (1997, pp.53-55). 
Beuchot (Posmodernidad, hermenéutica y analogía. pp. 1314), sostiene que a la aparición hoy de esa fuerte dosis de irracionalismo se debe a lo anterior. Este irracionalismo, continúa Beuchot (en esas páginas), privilegia desmedidamente, por decir algo, la imaginación, la intuición, la afirmación del deseo y la afectividad, y proclama la bancarrota del acceso objetivo al saber, del conocimiento y de los otrora fundamentos racionales o valores absolutos (metarrelatos) que han servido y pueden aún servir para distinguir la verdad de lo falso.

La epistemología ligth y el subjetivismo propio de la edad posmoderna pretenden, pues, suplantar a la epistemología "dura" peculiar de la edad moderna, la filosofía analítica y de las hermenéuticas de esa naturaleza; dicho de otro modo, la epistemología hermenéutica equívoca ${ }^{12}$ pretende hoy suplantar la epistemología hermenéutica unívoca que en sus ansias de "mismidad" su versión extrema defiende, vale recalcar, un único, exhaustivo, literal, puro y claro significado en el texto, un pensamiento científico y acceso al saber objetivista y otros valores epistemológicos modernistas. ${ }^{13}$

Aunque la posepistemología señalada arriba ha traído ciertos beneficios a favor de la hermenéutica textual bíblica en general, ${ }^{14} \mathrm{su}$ subjetivismo y escepticismo radicales, sin embargo, han conducido a otro callejón sin salida: el de la equivocidad relativista, reconocido por sus propios teóricos (por ej.: Vattimo, Lyotard y Gadamer) ${ }^{15}$ de este modo,

12 Hay quienes hasta dudan si la epistemología posmoderna sería epistemología genuina.

13 Cfr. P. Ricoeur, Hermeneutics \& the Human Sciences. pp. 45-48; M. BEUCHOT, Posmodernidad, hermenéutica y analogía. pp. 36-39; М. ВEUCHOT, Perfiles esenciales de la hermenéutica. pp. 21-24).

14 Por ejemplo, señalar los callejones sin salida de la epistemología moderna tales como la excesiva objetivación del sujeto (intérprete) que no añade nada nuevo a la realidad que se indaga, pues, según esta epistemología, éste se limita a reflejar las propiedades de esa realidad que indaga; en mi trabajo inédito, "Naturaleza del texto narrativo", he señalado ese aporte (y otros) que rescata el rol colaborativo del lector en el acto y proceso de interpretación, como piensa H. Eco, The Role of the Reader: Explorations in the Semiotics of Texts. Indiana, Indiana University Press, 1984, pp. 3-43), pero de un modo "analógico", a fin de evitar que sea bipolar: objetivante o subjetivante, al estilo moderno y posmoderno radical.

15 De ahí que hayan procurado refugiarse en la hermenéutica y en el diálogo dialéctico o circularidad hermenéutica (contextualizadora) en ella, en términos "razonable", prudencial, plausible y verosímil; es el caso de, por ejemplo, Schleiermacher, Gadamer y, en Latinoamérica, J. L. Segundo. Pero fallan, a mi modo de entender, porque, al desatender la analogía (excepto, y en alguna medida, Gadamer, quien enfatiza la "prudencia" en su hermenéutica; ver la nota 1), parecieran volverla equivocista y, sobre todo en Latinoamérica, con fuerte sabor ideológico; ver la propuesta de J. L. Segundo, en A. ROLDÁN, «El círculo hermenéutico en las teologías de Juan Calvino y Karl Barth», en A. ROLDAN, Reino, política y misión, Lima, Puma, 2011, pp. 125-155. 
en ciertos contextos hermenéuticos bíblicos, se han propiciado perspectivas cuestionables anárquicas y violentas tanto como una toma de poder; por ejemplo, privilegiar una interpretación que rehúye, por un lado, del rigor en aras de la "edificación espiritual", pero sin importar y recordar, respectivamente, si se abusa o no del texto y que la hermenéutica, aún dependiendo de la gracia y luz del Espíritu Santo, es un trabajo filosófico-cognoscitivo y comprensivo-explicativo, $y$, por el otro, del esfuerzo por un acto y proceso hermenéutico-exegético intelectivo responsablemente analógico y por alcanzar en ese acto y proceso algún grado de objetividad que ayude a entender suficientemente al texto. El precio pagado por esas perspectivas muchas veces ha sido la falta de una ética hermenéutica que conduce no sólo al anarquismo y la superficialidad en la interpretación del texto bíblico, sino también al equivocismo irresponsable que lleva a la vez a asignársele a ese texto muchos argumentos frecuentemente cuestionables, por basar el acto y proceso de interpretación desmedidamente sobre aquello que se supone es la luz del Espíritu: la experiencia o la intuición ideológica particular, sin que medie un esfuerzo por verificárselos, incluso con la comunidad de intérpretes, ${ }^{16}$ ni por recuperar algo del significado del autor o del hablante. Es mi opinión que un beneficio más de la posmodernidad es el esfuerzo por recuperar el pluralismo (la diversidad y diferencia, incluso en la hermenéutica) $;{ }^{17}$ en ese esfuerzo, sin embargo, corre el riesgo, en suma, de una apertura desmesurada que promueve el relativismo - que destruye a la misma hermenéutica y encierra contradicción semántica $^{18}$ - la hostilidad contra el rigor epistemológico y el saber, y la sobrevaloración del caos, de lo absurdo, del sin sentido o de lo banal. Si la epistemología unívoca era y es de una estrechez inadmisible, esta es, pues, todo lo contrario: excesivamente abierta.

La breve descripción anterior del escenario epistemológico de hoy apremia que en cada saber y, sobre todo, bajo la gracia y luz del Espíritu, en el hermenéutico bíblico - nuestro campo de interés- se vuelva a ese pensamiento o racionalidad intermedia entre la univocidad y la equivocidad: la analogía.

16 En la cual también la gracia y luz del Espíritu se ha manifestado, hermenéuticamente hablando.

17 El valor de esta pluralidad en la hermenéutica es porque, crítica y constructivamente, admite diversas corrientes en su tarea, en tanto contribuyen a la comprensión del texto.

18 "Contradicción semántica en los mismos términos que se unen, y en lo que se expresa; pues, paradójicamente, el enunciado que expresa el relativismo - a saber, que todo es relativo-, es él mismo un enunciado absoluto" (M. BEUCHOT, Perfiles presenciales de la hermenéutica. p. 25). 


\section{Epistemología analógica: Doctrina medieval de la significación}

A la luz de la fuerza con que la posepistemología está emergiendo y cada vez más influyendo hoy en nuestro contexto cultural y hermenéutico, habría que preguntarnos si realmente existe alguna alternativa epistemológica viable que haga del acto y proceso hermenéutico bíblico un acto y proceso equilibrado y respetuoso del texto.

Los teóricos del conocimiento hablan hoy de una epistemología antigua que, volviéndolo a decir, ha sobrevivido, informal y escondidamente, al lado de la univocista moderna y la equivocista posmoderna, $\mathrm{y}$ en reducidas hermenéuticas bíblicas y sociales contemporáneas. Esta epistemología es la analógica, considerada por Beuchot (2010, p. 127) y Mortensen (2012, p. i) una doctrina del significado, relacionada con la predicación lógica y mayormente con el campo de la lógica y filosofía del lenguaje; ${ }^{19}$ sobre todo, y como se verá, es una doctrina que presta hoy un servicio relevante a la hermenéutica, puesto que, frente al univocismo y equivocismo relativista extremo a los que ella ha oscilado y oscila hoy en su modo de entender los textos, la analogía se coloca en el punto intermedio entre ambos extremos epistemológicos, a fin de evitar el monolitismo univocista y el caos equivocista (M. BEUCHOT, Posmodernidad, hermenéutica y analogía pp. 35-45). Arguye Beuchot (Ibíd., p. 45):

Creemos que la postulación de la analogía es lo único que podrá salvar del monolitismo y del caos...Ya de suyo la hermenéutica parece tender a un analogismo sano que evite esos extremos. Es la posición ya anunciada por Aristóteles (tan tomado en cuenta por Ricoeur para establecer la importancia de la analogía, en su obra La metáfora viva) y que fue desarrollada por toda una tradición...Es una línea de pensamiento que podrá evitar la bancarrota epistemológica que nos amenaza como reacción al positivismo cientificista antes reinante.

La analogía es una doctrina medieval, aunque tuvo su origen mucho antes en la filosofía griega con los geniales pitagóricos (Beuchot, 2010, p. 128, citando a Ph. Sectetan, L'analogie, Paris. PUF, 1984, pp. 19 ss.). Esta doctrina, agrega Beuchot (2010, pp. 29-31, 125-132; 2005a, pp. 91-102; 2007, p. 22; 1996, p. 35), llegó a través de los neoplatónicos a la

19 Según J. R. MORTENSEN, Understanding St. Thomas on analogy. Lexington, The Aquinas Institute for the Study of Sacred Doctrine, 2012, permea también otros campos del saber filosófico como la ética y la metafísica. 
época Patrística, la Alta Edad Media y la Edad Media Madura, en las que fue usada y teorizada con gran fuerza, privilegiándose la de proporcionalidad, a veces la de atribución, y a veces combinaron ambas, como parece que es lo mejor. Sin duda, prosigue Beuchot $(2010$, p. 131 cp. Mortensen, 2012, p. 1), Santo Tomás de Aquino (1225-1274) -el principal representante de la escolástica medieval- fue quien, en la Edad Media Madura, ${ }^{20}$ da más cabida a la noción de analogía, a tal punto que llega a ser la clave de todo su sistema:

Santo Tomás comienza hablando de una analogía que es la menos propia, la cual tiende más a univocidad, pues en ella es mucha la semejanza y poca la diferencia. La llama "analogía según el ser y no según la intención" (secundum esse et non secundum intentionem). Es decir, los analogados son distintos según la realidad, pero no según el concepto (que es la intención de la mente). También la llama "analogía física", entendiendo por ello que no es analogía lógica. Además, dado que las cosas que son análogas de esta manera pertenecen al mismo género lógico, también la llama "analogía casi género" (analogia prope genus).

Sin embargo, opina Beuchot (2010, pp. 132-133, citando a Sto. Tomás, De veritate, q.9.a.7, ad 2), Aquino también retoma de Aristóteles la analogía de atribución y proporcionalidad. ${ }^{21}$ En esas mismas páginas, Beuchot interpreta esas dos clases de analogías:

20 Otros que la usaron en esa misma época fueron, entre otros, San Buenaventura, San Alberto Magno (maestro de Santo Tomás) y el dominico Eckhart, quien privilegió a la más platónica: la de "atribución". En la época pos-medieval del Renacimiento, la analogía fue usada por los seguidores de Aquino que la sistematizaron mejor y la revitalizaron, tales como Cayetano (Tomás de Vío), Francisco Suárez, Vico y algunos románticos. En las dos épocas que anteceden, la analogía fue usada en la obra Pseudo-Dionisio (Patrística) y por el traductor de esta obra Juan Escoto (Alta Edad Media). Ahora bien, aunque en este breve recuento histórico me quedo prácticamente en la época pos-medieval, por ser la analogía originaria de la Edad Media, recordar que ella ha llegado hasta a la nuestra contemporánea, si bien ya con poca fuerza (ver la nota 2 ).

21 "Se ha visto que Tomás", argumenta M. BEUCHOT, «Actualidad de la tradición filosófica: El caso de la doctrina de la analogía», en I. MURILLo (ed.), Actualidad de la tradición filosófica. Madrid, Diálogo Filosófico/Publicaciones Claretianas, 2010, p. 125), "al principio (Comentario a las Sentencias) usa más la analogía de atribución; pero después (De veritate) prefiere la de proporcionalidad; y luego vuelve a la de atribución, pero de manera diferente, esto es, a través de la doctrina de la participación. Es decir, llega a combinar y compaginar las dos"; por otro lado, en su análisis de doce textos originales del Aquinate (un derivado de Aquino), J. R. MORTENSEN, Understanding St. Thomas on analogy, pp. 83-133) alude esencialmente a estas mismas clases de analogías, pero su interpretación de las mismas es reducido al campo teológico (el ser de Dios) y metafísico (el ser humano), y, refiriéndose a la analogía de proporcionalidad "propia" (metonímica) e "impropia (la metafórica)", señala que, aunque hay ciertas evidencias que Aquino lo haya hecho tal división de la analogía, lo más evidente es que nunca lo hizo. 
La de atribución (que viene de los platónicos) ya era llamada así por Avicena, a través del cual llega a Tomás. Contiene un analogado principal, al que se atribuye el término de manera más propia. Los otros son analogados secundarios o menores, y el término análogo se les atribuye por participación del primero de todos ellos. La analogía de atribución puede ser extrínseca o intrínseca. A la extrínseca Tomás la llama "según la intención pero no según el ser" (secundum intentionem et non secundum esse). En ella la forma análoga sólo tiene ser en el analogado principal, los otros sólo se dicen tales, pero no lo son en realidad. La de atribución intrínseca es llamada por él "según la intención y según el ser" (secundum intentionem et secundum esse), porque la forma análoga se encuentra intrínsecamente no sólo en el analogado principal, sino también en los analogados menores, pero de manera diversa. Por otro lado, la analogía de proporcionalidad puede ser propia o impropia. La propia es una proporción de proporciones; por ejemplo, la razón es al hombre lo que el instinto al animal. La impropia o metafórica es la que se basa en alguna semejanza de acción o de efecto, como en la risa es al hombre lo que las flores al prado, y así entendemos la metáfora "el prado ríe".

Más concretamente, esos dos tipos de analogía desean colocarse en ese punto intermedio del que ya hemos hablado de dos modos: por proporción y por atribución.22 El primero, por proporción, estable relaciones de igualdad entre las porciones o partes $a, b=a$ ', b'. Y esas partes pueden ser literales o propias (metonímicas) como al decir: "(a) El instinto (b) es al animal, (a') lo que la razón (b') al humano"; se puede ver que, en cada una de las partes, el sentido es idéntico, no hay diferencia. Sin embargo, estas relaciones pueden ser también metafóricas o impropias como al decirse: “(a) La risa (b) es al humano, (a') lo que las flores (b') al jardín"; en este caso, se entiende que lo que el lenguaje figurado de las partes a' y b' quiere decir es que "el jardín ríe" (es decir, que da una sensación de alegría), pero el sentido es distinto (muy cerca de lo equívoco) en cada una de sus partes, ya que el jardín ríe de un modo diferente al humano.

El segundo modo, por atribución, establece cierta jerarquía respecto a la condición que se atribuye a un sustantivo determinado como cuando se atribuye primariamente al organismo humano la condición de "sano", para darse a entender que una persona está sana. Esta condición, sin embargo, puede atribuirse también al alimento, la medicina, al ambiente e, incluso, a la amistad, pues es posible que ésta sea o no sana; en estos casos, estas atribuciones son secundarias y, por ende, impropias;

22 En lo que sigue, en lo esencial, me apoyo en M. ВеUCHOT, Compendio de hermenéutica analógica. pp. 20-24 y 40-41; Perfiles esenciales de la hermenéutica, pp. 25-28, 49-54 y J. R. Mortensen, Understanding St. Thomas on analogy, con leves modificaciones; así que evado conscientemente la citación de las fuentes. 
de ahí que se pueda establecer la jerarquización siguiente: la salud es atribuida con mayor propiedad al organismo humano - el analogado principal-, pero con menos propiedad al alimento, y menos a la medicina, y menos al ambiente, y mucho menos a la amistad; así, se va descendiendo desde la atribución más propia a la menos propia. Aunque la atribución es válida en los últimos casos - los analogados secundarios-, en unos lo es más que en otros, pero muy cerca de lo igual o lo unívoco. ${ }^{23}$

Los dos modos anteriores en que la analogía establece relaciones permiten ver que ella posee un lado literal $\mathrm{u}$ objetivo y otro metafórico o subjetivo. Además, ellos permiten ver que la analogía respeta y, más aún, resalta lo diverso, es decir, lo fragmentario o lo equívoco, enfatizado por la epistemología equivocista posmoderna;24 pero, al mismo tiempo, ella respeta y resalta lo idéntico, lo unitario, lo semejante o lo unívoco, enfatizado por la epistemología univocista moderna. Es de este modo que la analogía se coloca en el punto intermedio entre la equivocidad y la univocidad, al decir lo que dice de un conjunto de cosas en parte idéntico y en parte distinto. Por eso, la analogía es igualdad proporcional y mediadora entre extremos, y no completamente equívoca ni completamente unívoca, pero participa de ambas.

\section{Contribución de la epistemología analógica a la hermenéutica narrativa bíblica}

Conforme lo anterior, podríamos argumentar, breve, tentativa y limitadamente, ${ }^{25}$ que la adopción de la analogía al acto y proceso

23 Recordar que la univocidad es la significación de un término respecto de todos sus significados; p. ej., "hombre" o "mortal" se aplican idénticamente a todos los hombres y a todos los mortales. La equivocidad, en cambio, es la significación diferente de un término respecto de todos sus significados: p. ej., "gato" se puede decir del animal, del sirviente y de la herramienta.

24 Por eso Beuchot, argumenta en todas sus obras que la analogía se inclinaría más por la diversidad o lo equívoco (lado metafórico de la analogía) que por lo idéntico o unívoco (lado metonímico de la analogía). Pero insisto que, al menos en la manera en que lo he planteado - que incluye la validación- no necesariamente puede ser así, pues, de lo contrario, se traicionaría el equilibrio que ella misma manifiesta; es ese equilibrio que la convierte en una hermenéutica analógica alternativa más viable y relevante frente a los univocismos y equivocismos a los que conscientemente o no tiende a desembocar hoy la tarea de interpretación bíblica.

25 Pues, entre otras cosas, no proveo ningún test case (caso de prueba) que muestre la funcionalidad de la analogía en un texto narrativo específico; pero espero en un próximo trabajo llenar ese vacío, recordando que en el campo bíblico 
hermenéutico narrativo nos permitiría al menos lo siguiente. Por un lado, al aplicar la analogía de proporción, nos permitiría discernir del texto varios énfasis teológicos, siempre y cuando sean proporcionalmente idénticos; de este modo, algunos de esos énfasis podrán ser legítimos o principales y otros, aunque posibles, podrán no serlo tanto, por lo que se debe sospechar o desenmascarar mucho más de estos últimos debido a que podrían ser falsos o impuestos sobre el texto. Pero todos se deben validar. Y para saber equilibrar con mayor efectividad es fundamental aquí, además de la guía del Espíritu, la virtud del juicio prudente que ha de reflejarse en la apertura al diálogo, incluso con otros y otras intérpretes y en la voluntad política de validar cada uno de los énfasis teológicos discernidos del texto. ${ }^{26}$

Por otro lado, al adoptar la analogía de atribución, nos permitiría la posibilidad de discernir varios énfasis teológicos legítimos del texto, pero esta vez jerarquizados, es decir, según niveles de validez o de adecuación al texto, es decir, que estén apoyados por los datos (por. Ej.: sintácticos e históricos) del texto, sin imposición o asalto. Pero aquí hemos de estar alertas porque habrá unos que serán más legítimos que otros, aunque todos ellos pertenezcan al conjunto de sentidos considerados válidos, como sucede cuando se interpreta un episodio bíblico desde ángulos diferentes. Así, en mi opinión, se podría evitar una hermenéutica-exégesis poético-narrativa excesivamente orillada ya sea al subjetivismo (equivocismo) o al objetivismo (univocismo), o, en su defecto, basada sobre la "distanciación" o "autonomía" del texto, que legitimen hasta los énfasis teológicos que prueben ser falsos. ${ }^{27}$ Aquí también, para saber analogizar o equilibrar con mayor efectividad, y evitar así lo anterior, es fundamental, además de la guía del Espíritu, el diálogo y el juicio

este esfuerzo está comenzando.

${ }^{26}$ La validación de una interpretación es una disciplina que requeriría un trabajo aparte. De ahí que sólo pueda argumentar aquí que hablar de validación es hablar de probabilidades cualitativas, no de precisión unívoca cuantitativa dogmática según el ideal empírico; pero esta validación impide el escepticismo, ya que provee un conocimiento de carácter científico del texto (P. RICOEUR, Hermeneutics \& the Human Sciences, pp. 210-215); el parámetro para medir la validez de una interpretación es, al final de cuentas, la intención del texto mismo en su forma final actual, pero en diálogo no sólo con el autor/narrador, el intérprete y la totalidad de la revelación escrita, sino también con la comunidad restante de intérpretes. Este diálogo ayudaría a obtener la proporción interpretativa de la analogía y evitar así interpretaciones falsas o de asalto al texto.

27 En este sentido, en nuestra propuesta, los diferentes y posibles sentidos del texto se deben por basar la hermenéutica-exégesis no sobre la premisa de la autonomía o liberación del texto de su autor y contexto de producción, sino sobre la analogía, la validación y, valdría agregar, la naturaleza tanto del acto y proceso de interpretación que es analógica o asociada a la sutileza (ver la nota 2). 
prudente que ha de reflejarse incluso en la voluntad política de validar los diversos énfasis teológicos.

Es claro que, a la luz de nuestro compromiso con la fe y el texto, lo que se busca en este esfuerzo es que, a pesar de la injerencia del o de la intérprete, el texto pueda hablar con mayor propiedad y libertad, y pueda así desplegar su potencial poder para confrontar, convencer y transformar. Este esfuerzo no intenta, pues, complicar ni simplemente intelectualizar el acto y proceso hermenéutico ni, mucho menos, volverlo cautivo de alguna tradición filosófica ni estética antigua o contemporánea, puesto que de suyo ese acto y proceso es, entre otras cosas, además de espiritual —dependiente del Espíritu-, naturalmente analógico, cognoscitivo, intelectivo, razonador y explicativo. Lo que procura es, en suma, de acuerdo con Beuchot («El casi de la doctrina de la analogía», p. 134), una modo de interpretación

que sepa recoger el ideal regulativo de la noción de analogía, que evita el rigor y la rigidez, hasta se podría decir: el anquilosamiento de las hermenéuticas unívocas, de corte positivista, y el relativismo extremo de las hermenéuticas equivocistas de corte posmoderno. Todo eso puede resaltar la vigencia y actualidad de esa idea de la analogía, ya que el estado mismo de la hermenéutica en la actualidad lo requiere, para salir de ese impasse en el que se encuentra y las polémicas, ya muchas veces estériles, que se entablan en su seno, por quedarse en los polos extremos y exagerados de las posturas que campean en el mapa de nuestra filosofía de hoy.

\author{
GeORGE REYES \\ MÉXICO, D.F. \\ george_reyes@email.com
}

